\title{
RESPONSE OF CsI:Pb SCINTILLATOR CRYSTAL TO NEUTRON RADIATION
}

\author{
Maria da Conceição Costa Pereira, Tufic Madi Filho, José Roberto Berretta, José Patrício Náhuel \\ Cárdenas and Antonio Carlos Iglesias Rodrigues
}

\begin{abstract}
The helium-3 world crisis requires a development of new methods of neutron detection to replace commonly used ${ }^{3} \mathrm{He}$ proportional counters. In the past decades, great effort was made to developed efficient and fast scintillators to detect radiation. The inorganic scintillator may be an alternative. Inorganic scintillators with much higher density should be selected for optimal neutron detection efficiency taking into consideration the relevant reactions leading to light emission. These detectors should, then, be carefully characterized both experimentally and by means of advanced simulation code. Ideally, the detector should have the capability to separate neutron and gamma induced events either by amplitude or through pulse shape differences. As neutron sources also generate gamma radiation, which can interfere with the measurement, it is necessary that the detector be able to discriminate the presence of such radiation. Considerable progress has been achieved to develop new inorganic scintillators, in particular increasing the light output and decreasing the decay time by optimized doping. Crystals may be found to suit neutron detection. In this report, we will present the results of the study of lead doped cesium iodide crystals (CsI:Pb) grown in our laboratory, using the vertical Bridgman technique. The concentration of the lead doping element $(\mathrm{Pb})$ was studied in the range $5 \times 10^{-4} \mathrm{M}$ to $10^{-2} \mathrm{M}$. The crystals grown were subjected to annealing (heat treatment). In this procedure, vacuum of $10^{-6}$ mbar and continuous temperature of $350^{\circ} \mathrm{C}$, for 24 hours, were employed. In response to neutron radiation, an $\mathrm{AmBe}$ source with energy range of $1 \mathrm{MeV}$ to $12 \mathrm{MeV}$ was used. The activity of the $\mathrm{AmBe}$ source was $1 \mathrm{Ci} \mathrm{Am}$. The fluency was $2.6 \times 10^{6}$ neutrons/second. The operating voltage of the photomultiplier tube was $1700 \mathrm{~V}$; the accumulation time in the counting process was $600 \mathrm{~s}$ and $1800 \mathrm{~s}$. The scintillator crystals used were cut with dimensions of $20 \mathrm{~mm}$ diameter and $10 \mathrm{~mm}$ height.
\end{abstract}

Key words: neutron detection, scintillator, crystals

All Authors: Nuclear and Energy Research Institute, IPEN-CNEN/SP Instituto de Pesquisas Energéticas e Nucleares - IPEN-CNEN/SP Av. Prof. Lineu Prestes 2242 Cidade Universitária CEP: 05508-000 São Paulo-SP - Brazil

Maria da Conceição Costa Pereira - macoper@ipen.br correspondent author Tufic Madi Filho - tmfilho@ipen.br

José Roberto Berretta - jirretta@ipen.br

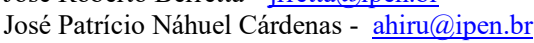

Antonio Carlos Iglesias Rodrigues - acirodri@ipen.br

\section{INTRODUCTION}

The disappearing inventory and minute natural abundance of ${ }^{3} \mathrm{He}$ gas necessitate the adoption of new technologies for the detection of neutrons. The exclusive source of ${ }^{3} \mathrm{He}$ on Earth is derived from the tritium stockpile, which decays to ${ }^{3} \mathrm{He}$ at a rate of $5.5 \%$ per year. Despite the low ${ }^{3} \mathrm{He}$ supply, and uncertain production rate in the future, this medium remains by far, the most attractive for many applications. The desired world deployment of the large area monitors to intercept the smuggling of nuclear materials, alone, could consume the entire ${ }^{3} \mathrm{He}$ supply, limiting the prospects of nuclear science and other applications that rely very heavily on ${ }^{3} \mathrm{He}$-based detectors. Clearly, alternate neutron detection technologies have to be developed. The inorganic scintillator crystal may be an alternative.[1]

Scintillators are materials that convert the energy of ionizing radiation into a flash of light. Scintillation material can be gaseous, liquid, glass-like, organic (plastics), or inorganic. In each case the material should be transparent to its own scintillation light. Inorganic wide band gap ionic crystals are the most widely used scintillators for detection of X-rays, gamma rays, and thermal neutrons. The scintillation method is widely used for detection of various kinds of ionizing radiation. The modern physics of scintillators is a broad field of fundamental and applied research dealing with a large variety materials and applications.[2] Every year, the scintillation method finds new applications in rapidly developing fields of high energy physics, nuclear medicine, geophysics, the monitoring of environmental, in devices and systems for security inspection.

There are many different luminescence species and scintillation mechanisms possible in inorganic materials. The luminescence may be intrinsic to material and involve electron-hole recombination; free, self trapped, and defecttrapped exciton luminescence; constituent transition group per post transition group ion fluorescence; core-valence band transitions; or charge transfer transitions within a molecular complex. Or it may be extrinsic, such as luminescence associated with impurities or defects and additive dopant íons. In the role of an activator, the dopant ion may be the luminescence species or may promote luminescence as in the case of defect bound exciton emission. [3,2]

Scintillators based on cesium iodide are the leading, among materials available for solid-state detectors. Cesium iodide based scintillators have high luminescence yield accompanied by high energy resolution and radiation stability. Various 
impurities have benn incorporated into alkali halides and their effects on optical properties and radiation detection have been investigated. Ions such as $\mathrm{Tl}+, \mathrm{Br}^{-}, \mathrm{Li}^{+}, \mathrm{Pb}^{2+}$ has been the theme of pursuit in our laboratory, in the last years. In continuation, a systematic investigation has been carried out in $\mathrm{Pb}^{2+}$ doped cesium iodide crystal to neutron response and the results are discussed in this article.

\section{MATERIAL AND METHODS}

Lead doped cesium iodine crystals (CsI:Pb) were grown in our laboratory, using the vertical Bridgman technique. $[4,5,6]$ The concentration of the lead doping was in the range $10^{-2} \mathrm{M}$ to $5 \times 10^{-4} \mathrm{M}$. The crystal grown were subjected to annealing (heat treatment). In this procedure, vacuum of $10^{-6} \mathrm{mbar}$ and continuous temperature of $350^{\circ} \mathrm{C}$, for 24 hours, were employed. Others details on the detector fabrication and characteristics may be found in our previous publication [7 ].

In the study of response to neutron radiation, the crystals were directly coupled to the photomultiplier tube using silicone grease viscosity of $0.5 \mathrm{McStokes}$, as optical interface. This ensured uniform refractive index across the contact surface between the crystal and photomultiplier tube. Sides of the crystals, which were not in contact with the photo-sensor, were covered with several layers of polytetrafluoroethylene (PTFE) tape to ensure good reflection of light. The electronic modules used for the processing of signals from the photomultiplier tube were constituted by conventional ORTEC electronics. The detection efficiency of the scintillator crystal was measured in two different positions: in the first (position I), the AmBe source was positioned at a distance of $100 \mathrm{~mm}$ from the photomultiplier tube. In the second (position II), the $\mathrm{AmBe}$ source was positioned at a distance of $100 \mathrm{~mm}$ from the photomultiplier tube, using $70 \mathrm{~mm}$ paraffin block as the interface. A foil of Cd was placed around the detector and the photomultiplier tube was used to avoid the scattered neutron contribution, as shown in Fig.1.

The fluency was $2.6 \times 10^{6}$ neutrons/second. The operating voltage of the photomultiplier tube was $1700 \mathrm{~V}$; the accumulation time in the counting process was $600 \mathrm{~s}$ and $1800 \mathrm{~s}$. The scintillator crystals used were cut with dimensions of $20 \mathrm{~mm}$ diameter and $10 \mathrm{~mm}$ height.

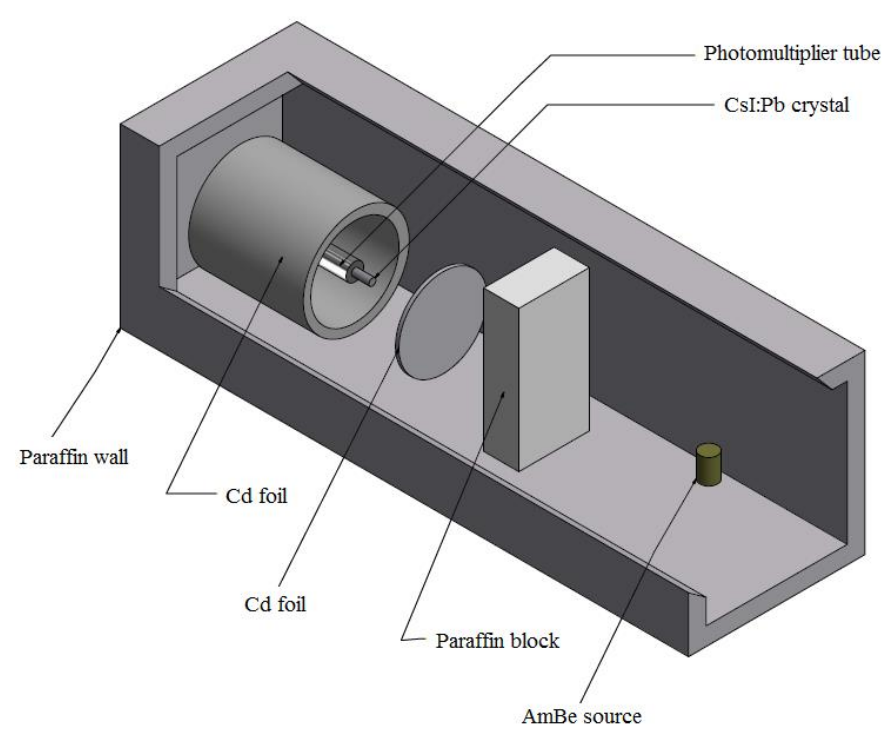

Fig. 1 - Exploded schematic representation of the array used for measurements, (position II).

\section{RESULTS}

Figure 2 shows the CsI: $\mathrm{Pb}$ crystal grown by the vertical Bridgman technique in our laboratory.

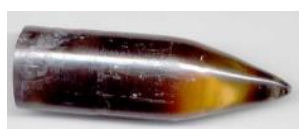

(a)

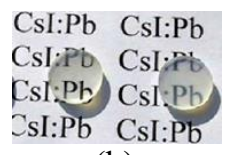

(b)
Fig. 2 - CsI:Pb crystal with molar fraction $10^{-2}$ grown by the vertical Bridgman technique. (a) before the heat treatment; (b) after heat treatment and polishing.

The curve shown in Fig. 3 illustrates the experimental results for the neutron radiation from an AmBe source using the $\mathrm{CsI}: \mathrm{Pb} 10^{-2} \mathrm{M}$ scintillator crystal. In order to verify the the response to fast and thermal neutrons, a block of $70 \mathrm{~mm}$ of paraffin was used. A Cd foil was placed around the detector and the photomultiplier tube, to avoid the scattered neutrons contribution. 


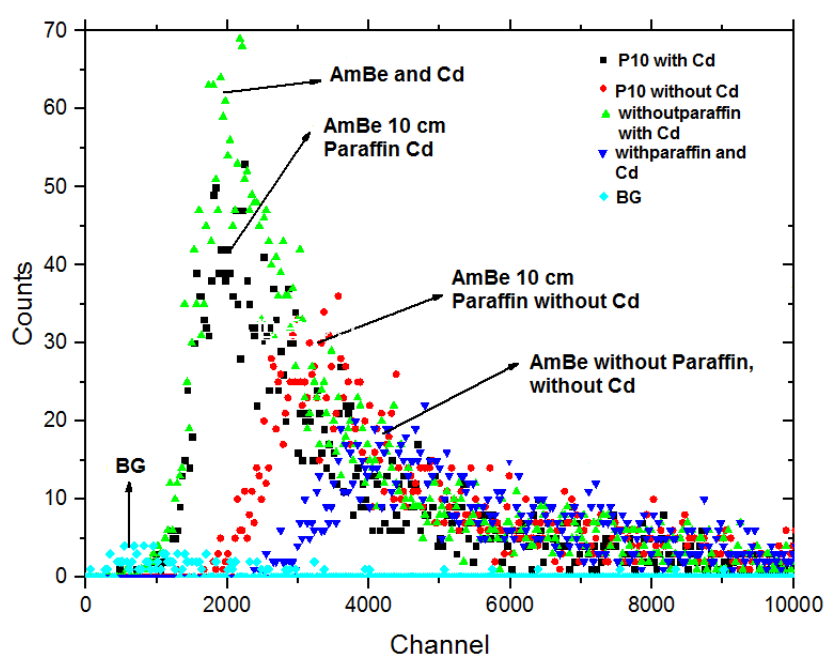

Fig. 3 - Results of the measurements using CsI:Pb crystal $10^{-2} \mathrm{M}$ and neutron source, with paraffin, without paraffin, with $\mathrm{Cd}$ foil and without $\mathrm{Cd}$ foil.

Fig. 4 shows the experimental results using $\mathrm{CsI}: \mathrm{Pb}$ with concentration $10^{-2} \mathrm{M}, 10^{-3} \mathrm{M}$ and $5 \times 10^{-4} \mathrm{M}$, without paraffin and without $\mathrm{Cd}$ foil.

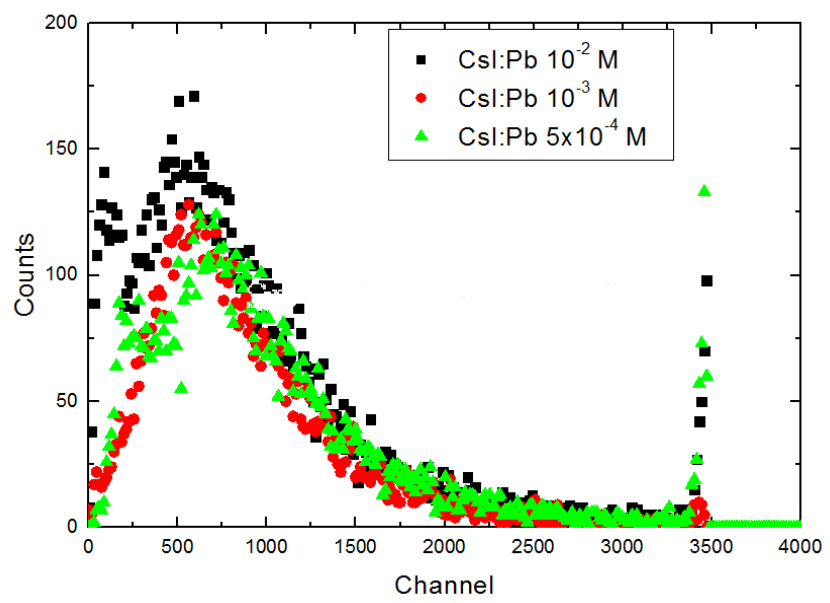

Fig. 4 - Results of the measurements using $\mathrm{CsI}: \mathrm{Pb}$ crystal and neutron source, without paraffin, with $\mathrm{Cd}$ foil.

\section{CONCLUSION}

The addition of the lead ions $\left(\mathrm{Pb}^{2+}\right)$ to the CsI matrix resulted in crystals with promising results, when excited with neutron radiation. The crystal showed sensitive to fast and thermal neutron.
In the dopant concentration range $(\mathrm{Pb})$ studied, the best neutron detection efficiency was obtained for the molar fraction $10^{-2}$, without the use of paraffin between the source and the crystal and using cadmium.

In the experiment with the crystals at various concentrations of the dopant, without the paraffin block between the detector and the neutron source, a slight increase was observed in the counts as a function of the increase in the concentration of dopant $\mathrm{Pb}$.

\section{REFERENCES}

[1] A. J. PEURRUNG, Recent developments in neutron detection. Nuclear Instruments \& Methods in Physics Research. A 443, pp. 400-415, 2000.

[2] G. F. KNOLL, Radiation Detection and Measurement, John Wiley \& Sons, New York, NY, USA, $4^{\text {th }}$ edition 2010.

[3] S. E. DERENZO, M. J. WEBER, E. B. COURCHESNE and M. K.KLINTENBERG. The quest for ideal inorganic scintillator. Nuclear Instruments \& Methods in Physics Research. A 505, pp. 111-117, 2003.

[4] P. W. BRIDGMAN, Proc. Amer. Acad. Arts Sci.,60, pp. 303-383, 1925

[5] M. C. C. PEREIRA, T. M. FILHO, J. P. N. CARDENAS. Inorganic Scintillation Crystals for Neutron Detection. IEEE Transactions on Nuclear Science, v. 63, pp. 1699-1702, 2016.

[6] M. C. C. PEREIRA, T. M. FILHO, Scintillation Characteristics of CsI Crystal Doped Br under Gamma and Alpha Particles Excitation. Materials Sciences and Applications (Print), v. 05, pp. 368-377, 2014.

[7] M. C. C. PEREIRA, T. M. FILHO, M. M. HAMADA. The effect of $\mathrm{Pb}^{2+}$ dopant in the crystal of CsI and its application as scintillation detector: a study of alpha particles. Radiation Effects and Defects in Solids (Print), v. 167, pp. 921-928, 2012

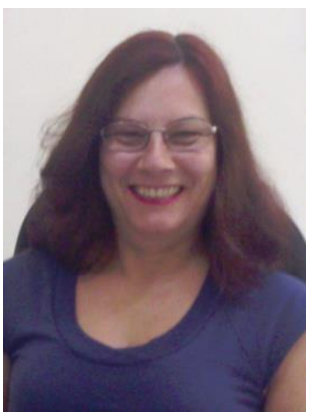

Maria da Conceição Costa Pereira: Graduated in Industrial Chemistry from the Escola Superior de Química Oswaldo Cruz, São Paulo, Brazil in 1985. Master in Nuclear Technology from the Universidade de São Paulo in 1997. $\mathrm{PhD}$ in Nuclear Technology from the Universidade de São Paulo in 2006. Currently is senior Researcher of the Instituto de Pesquisas Energéticas e Nucleares - Comissão Nacional de Energia Nuclear (IPEN/CNEN-SP). Has experience in Chemistry and Nuclear Engineering, acting on the following topics: radiation detectors, luminescence decay time, growth scintillators crystals. Working in the development of new materials and their applications in radiation detectors. Address to the curriculum http://lattes.cnpq.br/0977986453736808 
Tufic Madi Filho: Graduated in Physics from the Pontifícia Universidade Católica de São Paulo (1976). Master in Nuclear Technology from the Universidade de São Paulo (1982) and $\mathrm{PhD}$ in Nuclear Technology from the Universidade de São Paulo (1999). Currently is senior Researcher of the Comissão Nacional de Energia Nuclear (National Commission of

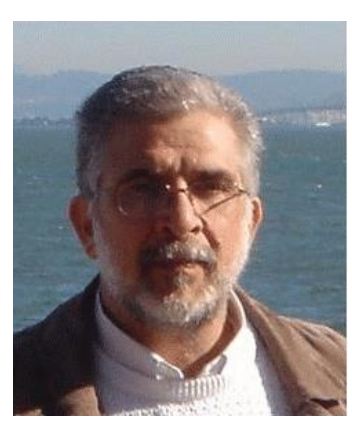
Nuclear Energy and Professor of the graduate course: "Theoretical Fundaments and Practices of the Instrumentation used in Nuclear Data Acquisition". Has experience in Physics, with emphasis on nuclear physics. Works on the following topics: nuclear reactor; alpha, beta and neutron detection, gamma spectrometry. Address to the curriculum

http://lattes.cnpq.br/3251192790149021.

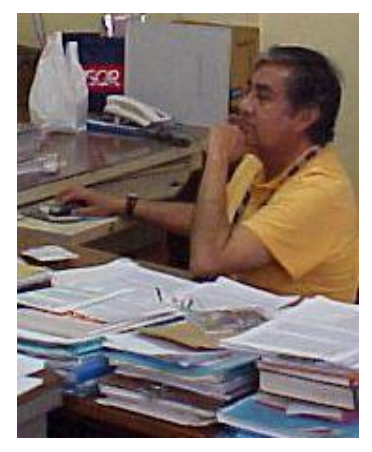

Professor of the course: Dr. José Patrício Náhuel Cardenas, Doctor of Science in Nuclear Technology, University of Sao Paulo, Brazil. Works in the development of neutrons experiments using IPEN laboratories and facilities, on a postgraduate program to support students in the use of instrumentation applied to nuclear research. 